\title{
NILAI SPIRITUAL TRADISI BAKTI MARGA DALAM PERSPEKTIF BUDDHIS
}

\author{
Rosalina Desi Paramita \\ STAB Negeri Raden Wijaya \\ Email: kumaracitta@gmail.com
}

\begin{abstract}
Abstrak
Penelitian ini dilatarbelakangi oleh keunikan sebuah ritual umat Buddha tangap warso wulan Suro (peringatan satu suro). Nilai Spritual Tradisi Bakti Marga Dalam Perspektif Buddhis Sebagai bentuk Bakti pada leluhur dan tradisi untuk tetap melestarikan kebudayaan. Penelitian ini merupakan penelitian Kualitatif. Teknik pengumpulan data menggunakan observasi, wawancara, dan dokumentasi. Subyek penelitian ini adalah sesepuh umat Buddha. Data penelitian ini dianalisis dengan teknik analisis model interaktif, terdiri dari pengumpulan data, reduksi data, penyajian data dan penarikan kesimpulan atau verifikasi. Hasil penelitian menunjukan bahwa: (1) Tradisi Bakti marga merukapan ritual yang telah mendarah daging untuk masyarakat Dukuh Karang Boyo: (2) Tradisi Bakti Marga ini sebagai sarana untuk penghormatan terhadap Leluhur: (3) Tradisi Bakti marga ini merupakan rangkaian kebudayaan Lokal yang dikolaborasikan dengan Buddhis untuk memperingati Tahun baru Jawa. Tradisi Bakti Marga dilaksanakan setiap malam Satu Suro dengan istilah metuk tanggal Jawa 1 Suro atau ambal warso. Tradisi ini merupakan Kolaborasi antara Kebudayaan Jawa dan konsep tataritual Buddhis.
\end{abstract}

Kata Kunci: Nilai Spiritual, Bakti Marga, Buddhis

\begin{abstract}
This research was motivated by the uniqueness of a Buddhist ritual tangap warso wulan Suro (commemoration of one suro). Spiritual Value of the Bakti Marga Tradition in the Buddhist Perspective is a form of devotion to the ancestors and traditions to preserve culture. This research was a qualitative research. Data collection techniques used observation, interviews, and documentation. The subjects of this study were Buddhist elders. The data of this study were analyzed using interactive model analysis techniques, consisting of data collection, data reduction, data presentation and drawing conclusions or verification. The results of the research showed that: (1) The tradition of Bakti marga was ingrained rituals that had been ingrained for the community of Karang Boyo Hamlet: (2) The tradition of Bakti marga as a means of honoring Ancestors: (3) The tradition of Bakti marga was a series of local cultures collaborated with Buddhists to commemorate the Javanese New Year. The Bakti Marga tradition is held every night of the One Suro with the term Javanese term 1 Suro or ambal warso. This tradition is collaboration between Javanese culture and Buddhist tataritual concepts.
\end{abstract}

Keywords: Spiritual Values, Bakti Marga, Buddhist 


\section{PENDAHULUAN}

Negara Indonesia merupakan negara kepulauan yang terdiri dari kesatuan pulau kecil maupun besar. Wilayah Kesatuan Negara Indonesia yang terdiri dari banyak pulau menjadikan Indonesia dihuni oleh berbagai suku bangsa yang mempunyai kebiasaan atau adat istiadat yang beranekaragam. Sujarwa (1998:10-11), kebudayaan adalah "seluruh sistem gagasan tindakan dan hasil karya manusia untuk memenuhi kehidupannya dengan cara belajar, yang semuanya tersusun dalam kehidupan masyarakat”. Kebudayaan antara daerah satu dengan daerah lain sangatlah berbeda. Kebudayaan dalam suatu daerah mencerminkan perilaku masyarakat setempat termasuk upaya masyarakat untuk melestarikan warisan leluhur yang telah berumur ratusan tahun. Kebudayaan sering dikaitkan dengan hal-hal yang berbau mistis, karena banyaknya masyarakat yang percaya akan Animisme dan Dinamisme khususnya pada masyarakat Jawa.

Budaya Jawa pada perkembanganya seolah-olah semakin menyusut dalam kemajuan zaman. Kebudayaan Jawa pada perkembangan ini sudah dikalahkan oleh adanya kemajuan teknologi yang dapat menghadirkan macam corak kesenian dan kebudayaan. Sebagai wujud pelestarian kebudayaan Jawa perlu dikembangkan eksistensinya. Masyarakat Jawa masih menjunjung tinggi nilai kebudayaan hal tersebut dibuktikan dengan masih banyaknya ritual-ritual yang mereka laksanakan. Ritual tersebut antara lain upacara peringatan 1 Sura, upacara perkawinan, Mitoni, Nyadran (upacara Bersih Desa), Tolak Hujan, dan masih banyak hal lain. Menurut Kamus Besar Bahasa Indonesia (2005:1208), tradisi adalah kebiasaan turun temurun (dari nenek moyang) yang masih dijalankan dalam masyarakat”. Salah satu tradisi yang sampai sekarang masih berkembang di tengahtengah masyarakat di Dukuh Karang Boyo, Desa Sampetan, Kecamatan Ampel, Kabupaten Boyolali adalah tradisi Bakti Marga yang dilaksanakan setiap malam satu suro dengan patokan kalender jawa.

Ritual tradisi Bakti Marga merupakan salah satu wujud kebudayaan yang dilakukan oleh masyarakat Jawa terutama di Dukuh Karang Boyo. Hal tersebut karena masyarakat Jawa tidak dapat terlepas dari suatu keyakinan atau kepercayaan beserta aspek-aspek di dalamnya. Masyarakat Jawa sulit melepaskan diri dari aspek kepercayaan 
pada hal-hal tertentu yang telah berlangsung secara turun-temurun. Sikap tersebut merupakan bentuk sikap masyarakat terhadap warisan leluhur dan merupakan sikap yang dominan dalam kehidupan masyarakat Jawa.

Tradisi Bakti Marga mempunyai makna dan nilai-nilai spiritual di dalamnya. Tradisi ini dilakukan khusus oleh warga umat Buddha di Dukuh Karang Boyo dan khususnya umat Buddha di Desa Sampetan. Tradisi Bakti Marga merupakan sebuah tradisi yang dilakukan oleh masyarakat Buddhis di Dukuh Karang Boyo, Desa Sampetan, Kecamatan Ampel, Kabupaten Boyolali. Hal tersebut membuktikan bahwa setiap tradisi yang dilakukan oleh masyarakat mempunyai makna dan nilainilai spiritual di dalamnya. Berdasarkan latar belakang tersebut peneliti tertarik untuk mengadakan penelitian mengenai nilai-nilai spiritual tradisi Bakti Marga di Dukuh Karang Boyo, Desa Sampetan, Kecamatan Ampel, Kabupaten Boyolali disebabkan beberapa hal. Pertama, tradisi Bakti Marga masih dilestarikan oleh masyarakat Buddhis di Dukuh Karang Boyo, Desa Sampetan, kecamatan Ampel, Kabupaten Boyolali. Kedua, dalam tradisi tersebut terdapat simbol-simbol yang memiiki nilai filosofi yang dapat dikaji dengan teori semiotika. Selain itu, penelitian tersebut berkaitan bidang ilmu yang berhubungan dengan kebudayaan dengan kompetensi tambahan sosiologi dan antropologi yang selaras dengan tuntutan visi misi Prodi Kepanditaan sekaligus sebagai pengetahuan dari Penulis yang saat ini dalam penyelesaian Tugas akhir sebagai Mahasiswa Prodi Kepanditaan.

\section{METODE}

Penelitian ini menggunakan pendekatan studi kualitatif dengan menggunakan model studi kasus karena dalam penelitian ini berusaha mengungkap tentang suatu perilaku, adat istiadat dan pandangan hidup kelompok yang diamati. Penelitian ini terbatas pada satu tempat di Dukuh karang boyo, Desa Sampetan, Kecamatan Ampel, kabupaten Boyolali. Adapun teknik yang dipakai dalam penelitian ini adalah teknik wawancara, dokumentasi dan observasi.

\section{PEMBAHASAN}

Pada era setelah kemerdekaan umat Buddha di Sampetan belum mempunyai Vihara untuk melakukan puja Bakti. Puja Bakti dilakukan di Goa, yang diberi nama 


\section{Sabbhata Yatra}

Jurnal Pariwisata dan Budaya

Volume 1 Nomor 1 Juli 2020

Goa Lowo. Konon diceritakan oleh warga dan pelaku ritual di Gua tersebut, walau goa itu kelihatan kecil dan sempit namun jika di isi banyak umat pasti tetap muat. Penyebaran Agama Buddha di tempat itu mendapat respon yang sangat baik oleh para masyarakat Desa Sampetan, hal itu terbukti pada tahun-tahun tersebut jumlah umat Buddha sangat Banyak mencapai Ratusan kepala Keluarga. Perjalanan untuk menuju Goa Lowo sangat jauh dan agak naik ke Gunung tetapi itu tidak membuat patah semanggat Umat Desa Sampetan, karena mereka memiliki Semangat yang sangat luar biasa untuk mendengarkan Dharma oleh Romo Pramono (wawancara dengan Mbah Narto, dirumahnya pada tanggal 08 Juni 2018).

Perkembangan Agama Buddha awal di Sampetan dengan menerima wejangan Dharma oleh Romo Pramono yang dilakukan di Guo Lowo. Selain wejangan Dharma secara lisan yang diberikan Romo Pramono aktifitas tersebut berkembang dengan metode lain. Perkembangan agama Buddha di Sampetan ini diprakarsai dan selalu muncul aktifitas baru sebagai bentuk perkembangan ajaran tersebut. Perkembangan ini juga dilakukan di Guo Lowo dengan pertapaannya Beliau Romo
Pramono di Guo tersebut dan berhasil menciptakan tata riltual Puja Bhakti dengan Versi Paritta Bahasa Ibu ( paritta Bahasa Jawa) dengan diperindah dengan nuansa lagu Kejawen ( lagu nuansa Jawa).

Perkembangan Agama Buddha mendapat perhatian dari pihak pemerintah desa Sampetan, Sehingga pada saat itu bapak Lurah memberi tanah di pekarangan Balai Desa di bangun sebuah Vihara untuk Umat desa Sampetan yang di beri nama Vihara Buddha Sasana, itu merupakan Vihara pertama untuk umat Buddha Sampetan. Dari latar belakang sejarah inilah tradisi Bakti Marga ini tetap di Uri-uri (dilestarikan) karena memiliki banyak makna diantaranya sebuah penghormatan tonggak awal perkembangan agama Buddha dan juga sebagai budaya naluri orang Jawa sebagai wujud bakti terhadap budaya leluhur untuk memperingati tahun baru kalender Jawa.

\section{Tradisi Bakti Marga}

Tradisi ini dilakukan pada malam satu suro dengan istilah metuk tanggal Jawa 1 suro. Malam satu suro merupakan salah satu tradisi tahunan yang setiap tahunnya dilaksanakan oleh sebagian besar masyarakat jawa, khususnya masyarakat Jawa di daerah Yogjakarta, Surakarta dan 


\section{Sabbhata Yatra}

Jurnal Pariwisata dan Budaya

Volume 1 Nomor 1 Juli 2020

Solo. Malam satu suro merupakan

biasanya disebut malam satu suro atau Bakti pergantian tahun pada penanggalan kalender Marga masyarakat Karang Boyo Jawa. Sama halnya dengan Tahun baru menyebutnya, dan sejak sore itu dengan tanggal satu Muharam tahun Hijriah atau sama halnya dengan tahun baru masehi yang dimulai dengan tanggal satu pada bulan Januari tahun masehi. Satu suro bagian penting bagi kehidupan manusia khususnya orang Jawa.

Masyarakat Jawa masih menyakini malam satu suro sangat identic dengan nuansa mistis atau nuansa spritualnya sangat kental. Malam satu suro sangat berarti bagi orang Jawa, karena tidak saja memiliki dimensi fisik, perubahan tahun tetapi juga mempunyai dimensi spiritual. Orang Jawa yakin bahwa perubahan tahun Jawa bertepatan dengan tahun Hijriah, menandakan babak baru dalam kehidupan. Pada dasarnya masyarakat Jawa menjalani ritual malam satu suro dengan berbagai maksud, yang utama adalah mengharapkan perubahan hidup yang lebih baik di tahun yang akan datang dijalaninya.

Satu suro merupakan hari pertama dalam kalender Jawa di bulan Suro, dan bertepatan dengan Satu suro biasanya sesepuh menyampaikan masuk tanggal satu suro setelah melewati waktu pukul 16,00 diperingati telah memasuki tanggal satu mayararakat mempersiapkan untuk ritual yang proses berlangsungnya sampai selesai dini hari bahkan sampai munculnya sinar matahari dipagi hari. Malam satu suro memiliki banyak pandangan dalam masyarakat Jawa, hari ini dianggap keramat terlebih bila jatuh pada Jum'at legi. Untuk sebagian Masyarakat pada malam satu suro dilarang untuk kemana-mana kecuali untuk berdoa atau pun untuk melakukan ibadah lain. Bagi masyarakat Jawa, bulan suro sebagai awal tahun Jawa juga dianggap sebagai bulan sakral atau suci, bulan yang tepat untuk melakukan renungan, intospeksi dan untuk mendekatkan dengan yang Maha Kuasa, maka malam satu suro nilai spritualnya sangat tinggi.

Cara yang biasa digunakan masyarakat Jawa untuk berintropeksi adalah dengan lelakon, yaitu puasa ( Ngrowot, mutih, ngebleng, ngadem) dengan mengendalikan hawa nafsu, lelaku malam satu suro tepat pada pukul 00.00 masyarakat melakukan kelanjutan rangkaian ritual dengan cara lelaku ( prosesi mubeng Ndeso dengan arah Ngiwo dengan makna menyingkirkan mara bahaya), diadakan oleh 
Jurnal Pariwisata dan Budaya

Volume 1 Nomor 1 Juli 2020

Masyarakat dukuh Karang Boyo, Desa Sampetan, Kecamatan Ampel, Kabupaten Boyolali.

Tradisi saat Malam satu suro bermacam-macam tergantung dari daerah mana memandang hal ini, sebagai contoh Tapa Bisu, atau mengunci mulut yaitu tidak mengeluarkan kata-kata selama ritual ini, yang dapat dimaknai sebagai upacara mawas diri, berkaca pada diri atas apa yang dilakoninya selama setahun penuh, menghadapi tahun baru di esok paginya. Tradisi lainnya adalah Kungkum atau berendam di sungai besar, sendang atau sumber mata air tertentu, Ada juga Tirakatan dengan tidak tidur semalam suntuk dengan tuguran atau perenungan diri sambil berdoa. Diantara tradisi tersebut ada juga sebagian masyarakat yang menggunakan malam satu suro sebagai saat yang tepat untuk melakukan ruwatan. Sepanjang bulan suro masyarakat Jawa menyakini untuk harus bersifat eling ( inggat ) dan waspada. Eling artinya manusia harus selalu tetap inggat siapa dirinya dan dimana kedudukanya sebagai ciptaan tuhan. Sebagian masyarakat mempercayai pada malam satu suro, muncul kekuatan Gaib atau kekuatan yang tidak kasap mata. Dalam kegiatan Melek-melek atau Tirikatan misalnya disetiap perempatan masyarakat berkumpul untuk menggelar doa agar terhindar dari mara bahaya, mara petaka atau gangguan jahat.

Menurut pendapat Embah Narto Kaseri wawancara tanggal 08 Juni 2018 dirumah mbah Narto sebagai sesepuh di dukuh Karang Boyo Bakti Marga merupakan wujud rasa bakti atau penghormatan yang ditujukan kepada leluhur (leluri Danyang Semoro Bumi) di dukuh Karang Boyo dengan cara berjalan mengintari desa dengan berlawanan arah dari pradhaksina arah mengelilingi desa tidak searah dengan jarum jam ( arah Ngiwo ) dan membawa sebuah persembahan yang di letakan disebuah perempatan. Sedangkan Pradaksina merupakan penghormatan dengan mengelilingi objek dengan searah jarum jam dengan bersikap Anjali. Bakti Marga dilaksanakan pada malam satu suro, tepat pukul 00.00 atau jam 12 malam, waktu melakukan ritual mubeng Desa berjalan mengintari desa mereka membawa persembahan atau sesajen yang isinya ada Bunga, Hio, Lilin, dan intok-intok (uncek), sedangkan intok-intok (uncek) adalah sesajen dalam Bahasa jawa, itu berupa Tumpeng kecil, Bawang, Cabe Merah dan 
Terasi, sesajen ini biasanya di letakan di 7 perempatan di dukuh Karang Boyo".

Intok-intok (uncek) ini selain buat sesajen waktu Bakti Marga sering juga digunakan persembahan untuk memperingati hari Kelahiran (Weton) diri kita masing-masing. Masyarakat dukuh Karang Boyo berkeyakinan jika Bakti Marga dilaksanakan dengan Hikmat maka keselamatan, kebahagian, kedamaian, Rezeki lancar, Kesehatan dan Ketentraman dapat di perolehnya di kehidupan seharihari. Didalam Buddhis dikenal dengan Amisa Puja, yaitu Pemujaan dengan melakukan persembahan. Dengan melakukan Amisa Puja akan membuahkan banyak pahala, berupa usia panjang, kebahagiaan, dan kekuatan. Dhammapada 109.

Bakti Marga didukuh Karang Boyo berlangsung sejak tahun 1967 di lakukan oleh Embah Priyo Hartoyo sewaktu itu beliau menjabat Kepala desa,di damping oleh embah Niti tukimin dan Embah Narto Kaseri. Mereka bertiga yang mengawali awal mulanya Bakti Marga di dukuh Karang Boyo dan sampai sekarang masih dilestarikan oleh masyarak lingkungan tersebut.
Sebelum mubeng Desa dimulai umat melakukan sembahyang bersama-sama dengan menggunakan Parita Bahasa Ibu (bahasa Jawa). Tim pembawa puja yaitu para remaja membawa lilin, air, bunga, dupa dan buah secara bergantian untuk diserahkan kepada petugas altar dan ditaruh di altar Sang Buddha.

\section{Nilai-nilai Spritual dalam tradisi Bakti Marga dalam perspektif Buddhis}

Nilai spritual dalam pandangan buddhis yang terjadi dalam tradisi Bakti Marga yaitu;

a. Ritual mubeng Kampung, dilaksanakan berkeliling dukuh Karangboyo dan selorejo pada malam hari sebagai wujud dari bentuk perenungan untuk selalu introspeksi diri. Dalam pelaksanaaan Ritual Mubeng Desa atau mengelilingi kampung dalam ritual ini, semua peserta harus melakukan Tapa Bisu (tidak berbicara atau pun bersuara), serta tidak makan, minum dan merokok. Yang dapat dimaknai sebagai upacara mawas diri, berkaca pada diri atas apa yang dilakoninya selama setahun 
penuh, menghadapi tahun baru di esok paginya. Ritual Mubeng Kampung Kalau dalam Buddhis hampir sama dengan Pradaksina akan tetapi ritual Mubeng Kampung di sini dalam tradisi Bakti Marga tidak sama dengan pradaksina yang dilakukan pada peringatan waisak yaitu dengan searah jarum jam melainkan berlawanan jarum jam, itu bertujuan melawan mara bahaya.

b. Membawa persembahan atau sesajen yang diletakan diperempatan sekitar dukuh Karang Boyo-Selorejo, setelah sampai di perempatan sesepun membacakan doa-doa dilanjutkan membakar hio dan meletakan sesajen, isi sesajen berupa bungga, lilin, dan intok-intok( uncek), sedangkan intokintok(uncek) berupa tumpeng kecil, bawang merah, cabe merah, dan terasi, sesajen itu berisi hasil bumi dari masyarakat dukuh Karang Boyo dan Selorejo itu wujud dari rasa syukur terhadap alam dan penghormatan kepada leluhur. Dalam Buddhis dikenal dengan Amisa Puja yang berarti pemujaan dengan persembahan.

c. Lek-lekan (Tidak tidur semalam suntuk) adalah tradisi yang biasanya dilakukan oleh warga dukuh Karang Boyo setelah melakukan acara mubeng Desa. Sebagian besar masyarakat mempercayai pada malam satu suro muncul kekuatan gaib atau kekuatan yang tidak tampak oleh mata telanjang. Kegiatan Lekkan disini bisa di isi dengan melakukan Meditasi (Bhavana). Tujuan meditasi adalah memusatkan pikiran dan memenagkan pikiran.

d. Poso atau Atthasila Orang-orang, sebelum mengalami perkembangan jaman dulu mereka melakukan poso mutih tidak makan yang mengandung garam. Dalam perkembangannya saat ini beberapa masyarakat ada yang melakukan Atthasila. Puasa ini mempunyai makna Pengendalian diri, dan melakukan perbuatan baik dan benar. 
Dari ritual tradisi Bakti Marga sebagai manifestari dari rasa syukur dan malam penuh harapan agar kehidupan disetahun ke depan lebih baik, dari serangkaian tradisi diatas di percaya dapat mendatangkan berkah. Bagi masyarakat awam, peristiwa itu barangkali dipandang sebagai sebuah keanehan yang sulit dipahami. Namun bagi yang masih menyakini tentu tidak demikian.

\section{Makna dan simbol-simbol Buddhis yang terkandung dalam Tradisi Bakti Marga}

Penelitian ini nengambil objek penelitian penelitian berupa kegiatan keagamaan jadi banyak sekali simbol - simbol yang mempunyai Makna dalam konteks Buddhis yang terdapat dalam peringatan Bakti Marga, seperti berikut ini;

1. Patung Buddha

Patung Buddha merupakan ilustrasi Buddha Gautama yang di ukir di kuningan dan di letakan di tempat tertinggi di altar. Patung Buddha merupakan sarana puja utama, patung Buddha melambangkan keagungan Buddha dan Penghormatan kepadaNya. Patung
Buddha di altar merupakan bentuk komunikasi umat Buddha, keberadaan patung di atar ini menstimulasi umat Buddha untuk mengingat kesempurnaan, kelebihan dan sifat-siat mulia guru terbesar mereka. Penempatan patung Buddha, yang selalu lebih tinggi dari peralatan puja lainnya merupakan manifestasi pengabdian, cinta, dan rasa hormat umat Buddha kepada Sang Buddha. (Hasil Wawancara dengan Mbah Narto Kasri pada tanggal 09 Juni 2018 )

\section{Lilin}

Lilin yang di gunakan dalam sesaji atau dalam bahasa Agama Buddha di sebut dengan sarana Puja. Sebagai Sarana puja lilin mempunyai makna filosofis yang sesuai dengan ajaran Buddha. Lilin adalah benda yang mengeluaran cahaya, cahaya tersebut mewakii Dhamma dari Sang Buddha yang selalu memberi penerangan kepada semua makhluk. Selain itu, lilin juga menyimbolkan sebuah pengorbanan. Lilin mengorbankan dirinya sendiri, untuk memberi penerangan kepada pihak 
lain. Hal ini menyiratkan ajaran Sang Buddha mengenai dana atau memberi kepada makhluk lain yang membutuhkan tanpa memandang suku, agama, ras, golongan dan sebagainya. Dengan sifat liliin yang seperti itu, Sang Buddha menyarankan umat Buddha untuk dapat seperti lilin. Menjadi cahaya untuk makhluk lain, melakukan kebajikan, memberi kebahagiaan, pada makhluk lain

3. Hio atau dupa

Melambangkan .keharuman dan ketentraman. Adapun maksud yang tertuang adalah hendaknya kita menjaga keharuman nama pribadi, keluarga, juga ketentraman pribadi dengan cara menjalankan sujud manembah kepada Tuhan Yang Maha Esa secara hening dan eling.

\section{Bunga}

Sarana puja lainya yang bisa di altar puja adalah Bunga mawar Merah Putih melambangkan penghormatan terhadap Negara seperti Benderan Merah Putih kalu dalam jawa dikenal dengan ( Bopo Biyung Ibu pertiwi ). Dalam Buddhis Bunga secara filosofis mengambarkan ketidak kekalan. Dalam agama Buddha di kenal adanya sebuah Anica yang artinya selalu berubah, semua tidak kekal. Hal tersebut seperti yang terjadi pada bunga, hari ini kuncup, beberapa heri kemudian mekar, dan tampak sangat indah, namun beberpa hari kemudian akan layu dan gugur sedikit demi sedikit dan memudian mati. Sama halnya dengan tubuh manusia dan semua makhluk hidup, tidak ada satu pun yang kekal abadi, semua pasti mengalami kematian.

5. Air

Air lambang dari kesucian. Hendaknya kita selalu menjaga perasaan yang bersih dan bening, suci.

Air adalah yang sangat penting bagi umat Buddha yang diletakan di altar sebagai sarana puja dalam puja nakti, termasuk Ritual Bakti Marga. Air melambangkan kerendahan hati. Hal ini terlihat dari karakteristik air di sungai yang selalu mengalir dari tempat yang lebih tinggi menuju tepat yang lebih tendah. Selain itu air juga mewakili kemurniaan pikiran. Demikian juga manusia juga harus 
Jurnal Pariwisata dan Budaya

Volume 1 Nomor 1 Juli 2020

selalu rendah hati dan kemurniaan pikiran mereka. Air juga mewakili Dhamma, ajaran Sang Buddha yang bisa membersihkan kekotorn batin pikiran.

6. Buah

Maknanya adalah agar semua pekerjaan dan tindakan menghasilkan buah yang manis dan bermanfaat bagi semua makhluk. Buah juga diletakan di Altar puja. Buah dalam Agama Buddha juga menyimbolkan dari buah perbuatan (kamma), hasil dari kebajikan. Selain itu sebagai lambang menghormat kepada Sang Buddha. Buah - buahan mengingatkan umat Buddha saat ini kepada pengikut Buddha di ribuan tahun yang lalu ketika Beliau masih hidup. Pada saat itu, pengikut Sang Buddha sering memberi Buah untuk di makan oleh Sang Buddha. Dengan demikian, menempatkan buah di altar juga melambangkan cara umat Buddha mempertahankan Tradisi mereka.

\section{Tumpeng}

Sesaji yang diletakan di altar puja saat ritual Bakti Marga adalah tumpeng. Tumpeng agung adalah tumpeng khusus untuk Sang Maha Pencipta, sebagai bentuk pengabdian dan rasa syukur. Tumpeng adalah singkatan dari "Tumungkulo sing mempeng" jika ingin selamat rajinlah beribadah atau sembhyang. Semua tumpeng bentuknya lancip ke atas hampir mirip dengan stupa sehingga tumpeng juga bermakna simbul dari nirvana atau pencapain tertinggi,

\section{KESIMPULAN}

1. Pelaksanaan Tradisi bakti marga dilaksanakan setiap malam satu suro dengan istilah metuk tanggal Jawa 1 suro. Bakti Marga merupakan wujud Bakti atau penghormatan kepada leluhur (leluri Danyang Semoro Bumi) di dukuh Karang Boyo dengan cara berjalan mengintari desa dengan berlawanan arah dari pradhaksina mengelilingi desa tidak searah dengan jarum jam (arah Ngiwo) dan membawa sebuah persembahan yang di letakan disebuah perempatan. Bakti Marga dilaksanakan pada malam satu suro, tepat pukul 00.00 
Jurnal Pariwisata dan Budaya

Volume 1 Nomor 1 Juli 2020

atau jam 12 malam. Sebelum ritual Mubeng desa mereka melakukan kebaktian dengan menggunakan Bahasa Jawa( bahasa Ibu).

2. Bentuk nilai-nilai spiritual tradisi Bakti Marga dalam Perspektif Buddhis di dukuh Karang Boyo.

a. Ritual Mubeng desa, sebagai bentuk perenungan untuk selalu intropeksi diri. Didalam Buddhis hamper mirip dengan Pradaksina

b. Membawa persembahan atau sesajen bermaksud wujud rasa syukur terhadap alam dan penghormatan dengan leluhur.

Didalam Buddhis dikenal dengan Amisa Puja

c. Lel-lekan (tidak tidur) bermaksud memusatkan pikiran dan memenagkan pikiran. Di dalam Buddhis dikenal dengan Meditasi

d. Poso bermaksud pegendalian diri dan melakukan perbuatan baik. Dalam Buddhis dikenal dengan Atthasila

3. Makna simbol-simbol dalam konteks Buddhis yang terkandung dalam tradisi Bakti Marga, seperti Buddha rupang, lilin, bungga, dupa, air, buah dan tumpeng mempunyai makna penghormatan kepada leluhur,adhitthana, dama, annica, dan kamma.

\section{DAFTAR PUSTAKA}

Aman, Aifuddin. (2013).Tren Spritualtas Melenium Ketiga. Cetakan Pertama. Tangerang:Ruhama.

Arikunto. (2006). Prosedur Penelitian Suatu Pendekatan Praktik. Jakarta: Rineka Cpta

Hakim, Muhamad Nur. (2003). Islam Tradisionldan reformasiPragmatisme (Agama dalam pemikiran Hasan Hanafi). Malang: Bayu Media Publishng.

Haryanto. (2008). Dasar-dasar penulisan Proposa Penelitian. UGM: Gadjah Mada UniversityPress.

Hasan, A;liah B.p. (2006). Psiklogis Pekembangan Islam : Menyigka Renang Kehidupan Manusia dan Prkelahiran hingga Pascakematian. Jakarta: Raja Grafindo Persada.

Kurniawan. (2001). Semiologi Rolan $d$ Barthes Indonesi Tera, Magelang

Milles an Huberman, A. Michael. (1992). Anaisis Data Kwalitatif : Buku Smber tentang Metode-metode Baru. Jakarta ; UI Press

Moleong, Lexy J. (2013). Metodelogi enelitian Kwalitatif. Bandug: PT. Rmaja Rosdakara. 


\section{Sabbhata Yatra}

Jurnal Pariwisata dan Budaya

Volume 1 Nomor 1 Juli 2020

Mursal, sten. (1999). Kajian Tranformasi Budaya. Bandung: Angkasa

Piedmont, R.L. (1999). Does Sprituaiity Represent the Sixth Factor of Persnality? Spritual Transcendence and the Five-Factor Model Journal of Personality, December, (67:6). Oxford; Blackwell Publishers.

Piedmont, R.L. (2001). Spiritual Transeendence and the Scientific Study of Sprituaality, Journal of
Rehabilitatio, $67 \quad$ (1):4-14. Alexandria; National Rehabilition Counseling Association.

Rohman syah, Alfian. (2014). Studi dan Pen gajian Sastra: Perken alan Awal

Rosito, Asina. (2010). Spritualitas dalam Perspejktif Psijkologi Positif, jutnal Visi 18 (1): 29-42. 